\title{
Performance Prediction of a Hydrogen Production System Based on PV/T Technology
}

\author{
Zaiguo $\mathrm{Fu}^{1,}{ }^{*}$, Yongwei $\mathrm{Li}^{1}$, Xiaotian $\mathrm{Liang}^{1}$, Long Wang ${ }^{1}$ and Qunzhi Zhu ${ }^{1}$ \\ ${ }^{1}$ College of Energy and M echanical Engineering, Shanghai University of Electric Power, Shanghai 200090, China
}

\begin{abstract}
With the rapid development of hydrogen production technology by using solar energy, the research of Solid Oxide Electrolysis Cell (SOEC) and Photovoltaic/Thermal (PV/T) system have become popular. A design scheme of hydrogen production system based on PV/T technology was proposed. The electrolytic cell combined photovoltaic panels, trough solar collectors and multiple heat exchagers to improve the overall efficiency of the hydrogen production system. The efficiency was predicted based on empirical models. The results showed that the hydrogen production efficiency of SOEC increased with increasing temperature and with decreasing current density. However, the balance between energy efficiency and hydrogen production rate of SOEC needed to be taken into account. The predicted hydrogen production efficiency of SOEC and overall system efficiency also agreed well with the results available in literature.
\end{abstract}

\section{Introduction}

The large amount of pollutants emitted by burning fossil fuels, such as soot, carbon dioxide, sulfur dioxide, and nitrogen oxides, have caused serious pollution of the ecological environment and global warming. The energy industry focuses on the development and utilization of clean energy, with a view to changing the energy consumption pattern based on fossil fuels to achieve the purpose of reducing pollutants and greenhouse gas emissions.

Solar energy is more popular because of its inexhaustible and environmentally friendly features. It has been widely used in people's lives, such as solar cookers, solar cells and solar power stations. M eanwhile, hydrogen energy is gradually well-known to the public, and its raw materials and products are non-polluting water. M oreover, hydrogen also has the characteristic of high calorific value when burning. The heat energy generated by burning the same quality of hydrogen is about 3 times that of gasoline, 3.9 times that of alcohol, and 4.5 times that of coke [1].

Both solar energy and hydrogen energy are environmentally friendly and pollution-free energy. They can be linked to each other via the electricity or the heat. Solar thermal power generation technology and photovoltaic power generation technology are the two most common ways to use solar energy reasonably and photovoltaic/thermal (PV/T) is a photovoltaic-thermal integration technology [2]. The hydrogen production by electrolysis requires a large amount of electricity and thermal energy. Therefore, this study intends to propose a design scheme and to predict its performance for a hydrogen production system based on PV/T technology.

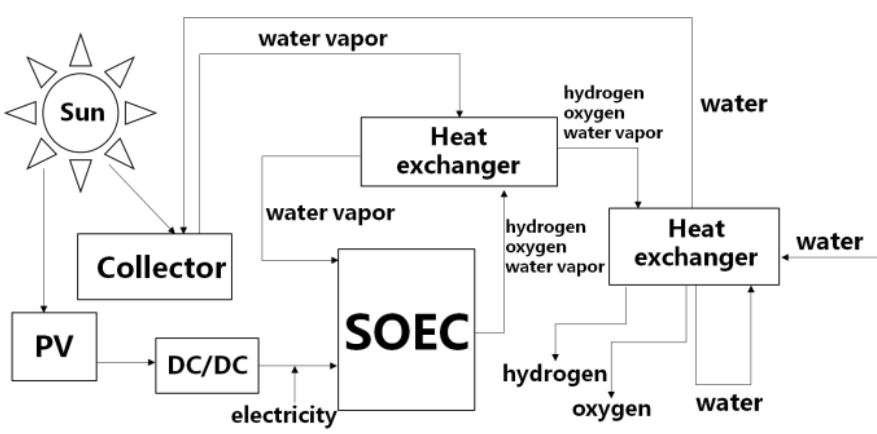

Fig. 1. Schematic of hydrogen production system based on PV/T Technology

\section{Modelling}

\subsection{Hydrogen production system}

The flow chart of the hydrogen production system based on $P V / T$ technology designed in the present study is shown in Figure 1. The system is mainly composed of solid oxide electrolysis cell (SOEC), solar heat collector, photovoltaic panel and two heat exchangers. A mong them, SOEC uses a cathode-supported flat-type electrolytic cell, the cathode material is $\mathrm{Ni}-\mathrm{YSZ}$, the anode material is LSM, the electrolyte material is $Y S Z$, and the connector material is $\mathrm{LaCrO}_{3}$. The photovoltaic cell is EG-250P60-C typed solar cell (250W). The collector uses trough solar collector. During the working process of the system, the photovoltaic panel receives the radiation of sunlight, thereby generating electrical energy, and then the electrical energy is provided to the electrolytic cell through a DC/DC booster. The trough solar collector produces water vapor to provide the heat

\footnotetext{
${ }^{*}$ Corresponding author: fuzaiguo@ shiep.edu.cn
} 
and resource required for electrolysis. SOEC produces hydrogen and oxygen through electrolysis. The heat exchanger is used to collect the waste heat of high temperature gas at the outlet of the electrolytic cell.

This system adds solar optical elements on the basis of the original high-temperature SOEC hydrogen production system. The innovation is that the hydrogen, oxygen and water vapor from the SOEC will release heat in the heat exchanger to cool down, and then enter the second heat exchanger to release the waste heat. The separated water and make-up water are heated in the double heat exchangers and the heat collector and then enter the electrolytic cell. Such staged heating and exothermic design can more thoroughly utilize the residual heat of the mixed gas to make the water vapor participating in the reaction have a higher temperature.

\subsection{Empirical models}

\subsubsection{Electrochemical analysis of electrolytic cell}

Assuming that the electrolysis process is reversible, the voltage applied on the electrode can be solved by the Canster equation. According to the empirical formula, it can also be calculated as follows:

$$
U_{\text {rev }}=-2.8993 \times 10^{-4} \mathrm{~T}+1.2099
$$

Where $T$ is the absolute temperature of the reaction process.

Nernst voltage $U_{\text {Nernst }}$ is expressed as follows:

$$
U_{\text {Nernst }}=U_{\text {rev }}+\frac{R T}{z F} \ln \left(\frac{p_{H_{2}} \sqrt{p_{\mathrm{O}_{2}}}}{p_{\mathrm{H}_{2} \mathrm{O}}}\right)
$$

Where, $z$ is the number of transmitted electrons ( 2 in water electrolysis), and $F$ is the Faraday constant. $p$ is the partial pressure.

The actual battery voltage is affected by many different overpotentials and is higher than the reversible voltage so that resistance can be overcome. It is expressed as:

$$
U_{\text {cell }}=U_{\text {Nernst }}+U_{c o n, c}+U_{c o n, a}+U_{a c t, a}+U_{\text {ohm }}
$$

Where, $U_{c o n, c,} U_{c o n, a}, U_{a c t, c}, U_{a c t, a}, U_{o h m}$ are the cathodic concentration overpotential, anode concentration overpotential, cathode activation overpotential, anode activation overpotential and electrolyte ohmic overpotential, respectively.

The hydrogen production rate ( ${ }^{\dot{H}_{2}}$ ) on a single cell can be calculated according to the electron transfer rate obtained from the current density on the basis of Faraday $\odot$ law. It is described as :

$$
\dot{m}_{H_{2}}=\frac{N_{\text {cell }} \times J \times A_{\text {cell }} \times M_{H_{2}}}{2 F}
$$

Where, $U_{\text {cell }}$ is the actual voltage, $J$ is the current density, $A_{\text {cell }}$ is the effective area of the battery, and $N_{\text {cell }}$ is the number of batteries.

The efficiency of solid oxide cell is given as:

$$
\eta_{\text {SOEC }}=\frac{\dot{m}_{\mathrm{H}_{2}} \times L H V_{\mathrm{H}_{2}}}{P_{\text {st }}+P_{\text {pump }}+P_{\text {cell }}}
$$

In the formula, the low calorific value of hydrogen $\left({ }^{L H V_{H_{2}}}\right)$ is $120210 \mathrm{~kJ} / \mathrm{kg}$, and $P_{s t}$ and $P_{\text {pump }}$ are the demand of reactor power and pump power respectively. Other parameters are cited from [3].

\subsubsection{Photovoltaic cell and solar thermal system}

Photovoltaic power output depends on the solar radiation intensity, the temperature of photovoltaic modules, the solar incident angle and the loading angle of photovoltaic panels. In order to predict the actual energy output, the most widely used five parameter model and solving method proposed by Zhang et al. [4] can be employed. The results are reliable and have higher accuracy. The parameters of adopted solar cell includes $P=250 \mathrm{~W}, V_{O C}=33.1398 \mathrm{~V}, I_{S C}=9.2914 \mathrm{~A}, I_{m}=$ 8.4717A, $V_{m}=25.2173 \mathrm{~V}$. The obtained results are $I_{p v}=$ 9.2984A, $I_{0}=729.52 \mathrm{nA}, R_{s}=0.339 \Omega, R_{p}=446.46 \Omega$, and $n=1.1791$.

For the calculation of solar thermal system, the water in the pipe flows axially, regardless of the fine radial movement. The pressure exerted on the fluid in various states is equal on all cross sections and the influence of gravity can be ignored for the horizontal heat pipe. Since the inlet and outlet temperatures are known, the total heat received by the fluid can be obtained, and then the inner pipe wall temperature can be calculated according to the average temperature. According to the relevant design and research, the outer wall temperature can be taken as $30^{\circ} \mathrm{C}$ and the average air temperature outside the tube can be taken as $20^{\circ} \mathrm{C}[5$, $6]$. The inner diameter, outer diameter and length of the endothermic tube are $55 \mathrm{~mm}, 70 \mathrm{~mm}$ and $98.5 \mathrm{~m}$ respectively. The heat flux of forced convection in the tube, the air convection heat flux, the outward radiation heat flux, and the total absorbed heat flux of the collector can be calculated according to the heat transfer theory. Thus, based on the actual absorbed solar radiation intensity, the efficiency can be obtained consequently.

The overall performance of the hydrogen production system can be evaluated via the total efficiency. It is defined as :

$$
\eta_{\text {overall }}=\frac{\dot{m}_{\mathrm{H}_{2}} \times L H V_{\mathrm{H}_{2}}}{Q_{\text {solar }}}
$$

Where, $Q_{\text {solar }}$ is the solar radiation energy absorbed by the system.

\section{Results and discussion}

\subsection{SOEC performance}

The obtained main cell polarization with the varying current density is shown in Figure 2. It can be seen that the largest irreversible voltage loss of the cell is the activation over potential, followed by the ohmic over potential, and the smallest is the concentration over potential. 
W ith the increase of current density, the irreversible loss increases, which leads to the decrease of energy efficiency. However, the hydrogen production rate is directly proportional to the current density. Therefore, in practical engineering application, we should make a trade-off between energy efficiency and hydrogen production rate. In the case of hydrogen production alone, energy efficiency can be biased. In the case that hydrogen production needs to be supplied to subsequent power generation and heating, hydrogen production rate can be biased. The previous results showed that the low hydrogen production rate caused by low current density will reduce the degradation rate of the battery and prolong the service life of the battery. Therefore, the design of the system should be considered between the efficiency, cost and hydrogen production rate.

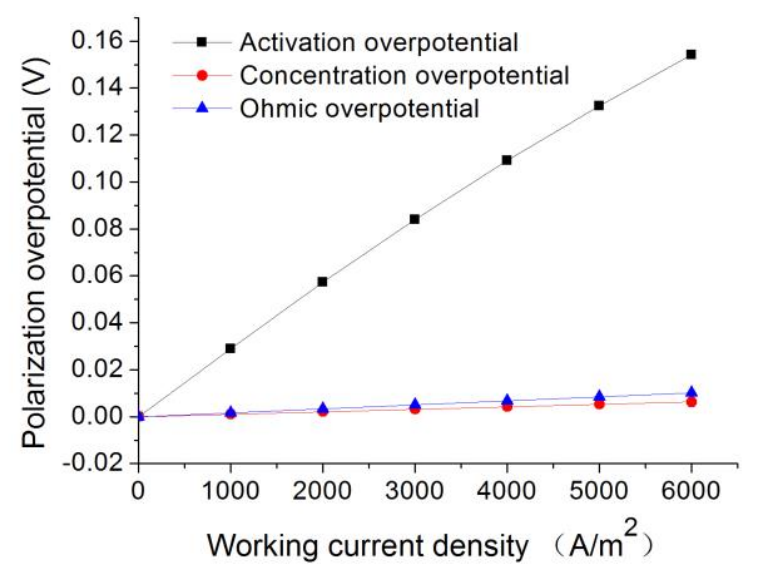

Fig. 2. Effect of current density change on cell polarization

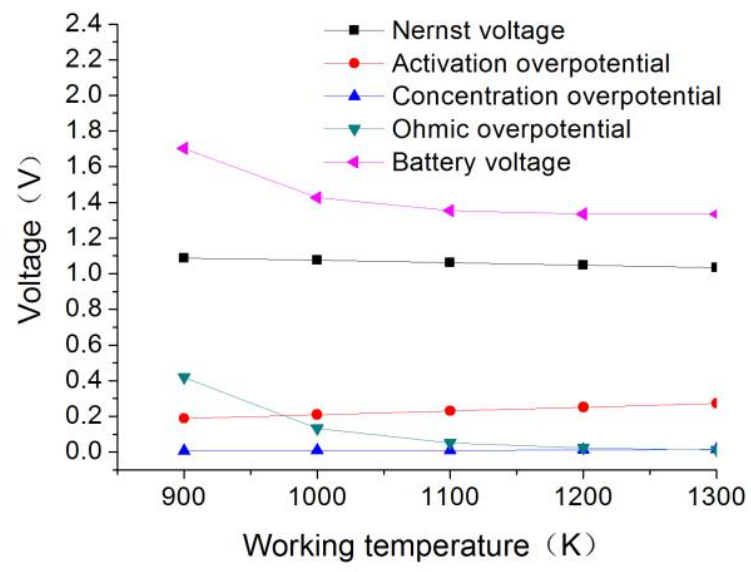

Fig. 3. Variation of different polarization overvoltage and battery voltage with operating temperature

Figure 3 shows the effects of operation temperature on polarization overpotential and battery voltage. It indicates that with the increase of temperature, Nernst voltage slightly decreases, activation overpotential slightly increases, concentration overpotential basically remains unchanged, ohmic over potential greatly decreases in the range of $900-1100 \mathrm{~K}$, and then decreases slightly. The battery voltage also shows a downward trend, falling rapidly in the range of 900-1100K, and then slightly down.

\subsection{System performance}

Figure 4 shows the rate of consumed electric energy to thermal energy. It can be seen that the proportion of consumed electric energy and thermal energy decreases with the increase of temperature, and gradually changes to the equal value. Further analysis indicates that the electric energy consumed per unit hydrogen production in high temperature cell is less than that in low temperature cell, and the heat energy is more.

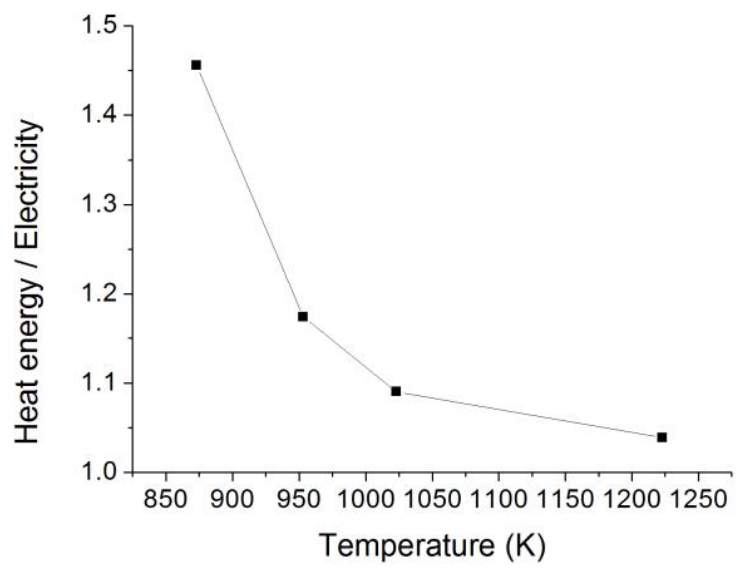

Fig. 4. Variation of power to heat consumption ratio with temperature

Figure 5 shows the variation of hydrogen production efficiency with current density. It can be seen that when SOEC is at $1223 \mathrm{~K}$ high temperature, the energy efficiency of the system continues to increase with the current density, and it can reach about $80 \%$ hydrogen production efficiency at $12000 \mathrm{~A} / \mathrm{m}^{2}$, and then gradually decrease. When the temperature is $873 \mathrm{~K}$, the energy efficiency of the system begins to decrease when the current density is about $6000 \mathrm{~A} / \mathrm{m}^{2}$, and the maximum hydrogen production efficiency is about $62 \%$.

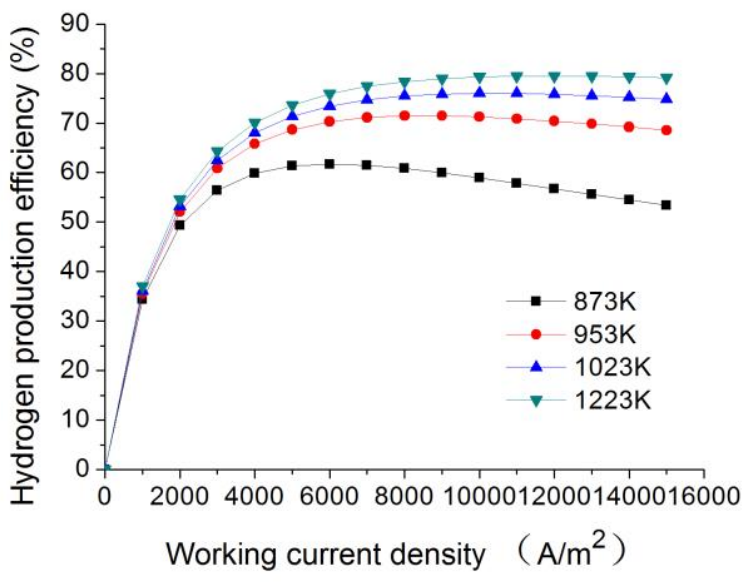


Fig. 5. Variation of hydrogen production efficiency with current density

The overall performance of the hybrid system is also evaluated based on three factors: the low heat value of hydrogen, the solar radiation energy absorbed and the hydrogen production rate in the solid oxide cell. By supposing that the operating pressure of the system is $5 \mathrm{MPa}$, the temperature of the mixture at the outlet of the electrolytic cell is $950{ }^{\circ} \mathrm{C}[2,3]$ and the working current density is $12000 \mathrm{~A} / \mathrm{m}^{2}$, the efficiency of solid oxide electrolyzer is $79.55 \%$, and the efficiency of hydrogen production system based on $\mathrm{PV} / \mathrm{T}$ technology is $34.08 \%$. These value are almost the same as the results reported in the literature [3].

\section{Conclusions}

In this work, the hydrogen production system based on $\mathrm{PV} \pi \mathrm{T}$ technology and the traditional high-temperature SOEC technology is proposed. M ultiple heat exchangers are added to make full use of solar thermal energy. Through the design and efficiency calculation of the system, the following conclusions are drawn:

(1) The activation, concentration and ohmic overpotential increase with the increase of current density. The activation overpotential is dominated in the irreversible voltage loss of the cell. The hydrogen production efficiency of SOEC increases with the increase of temperature and first increases and then decreases with the increase of current density.

(2) There is a trade-off between energy efficiency and hydrogen production rate in SOEC. With the increase of current density, the energy efficiency decreses and the hydrogen production rate increases. The rate of consumed electric energy to thermal energy decreases with the increase of temperature.

(3) The efficiency of the cell in the proposed system can be as high as $80 \%$ at a certain high temperature and current density. The total efficiency of the composite hydrogen production system is $34 \%$, indicating the reliability and good performance of the proposed system. rev

Nernst

con,c

con, $a$

act,c

act, $a$

ohm

cell

$\mathrm{H}_{2}$

st

pump

SOEC

overall

solar reversible state

open circuit voltage

cathode concentration polarization

anode concentration polarization

cathode activation polarization

anodic activation polarization

ohmic polarization

electrolytic cell

hydrogen

stack

pump

solid oxide electrolysis cell

total

solar energy

\section{Acknowledgement}

The support by the Science and Technology Commission of Shanghai Municipality (STCSM NO.18020501000) to this study is acknowledged and highly appreciated.

\section{References}

1. R. M a, Plant M ainte Eng.19, 126-128 (2017)

2. S. Zhou, Y. Wang, T. Hu, Z. Deng, A cademic meeting of China Society of Engineering Thermophysics, 196110, (2019)

3. D. Raheleh, M. Mehrpooya, Energy Convers. M anage. 176, 73-94 (2018)

4. S. Zhang, D. Chen, In for Res.44, 39-43 (2018)

5. Q. Chou, SEU., 37-91 (2016)

6. B.Y ang, TJU ., 23-54 (2011)

\section{Nomenclature}

$\begin{array}{ll}R & \text { universal gas constant } \\ A & \text { area, } \mathrm{m}^{2} \\ T & \text { temperature, }{ }^{\circ} \mathrm{C} \\ P & \text { heating power, } \mathrm{W} \\ Q & \text { heat quantity, } \mathrm{kJ} \\ \mathrm{F} & \text { the Faraday constant } \\ \mathrm{U} & \text { voltage } \\ z & \text { number of transmitted electrons } \\ N & \text { number of batteries } \\ n & \text { diode parameter } \\ J & \text { current density } \\ \dot{m}_{\mathrm{H}_{2}} & \text { rate of production } \\ \text { LHV } & \text { low calorific value } \\ \text { Greek letters } \\ \eta & \text { efficiency } \\ \text { Subscripts }\end{array}$

